observations add substance to the presumed involvement of serotonin in SAD. And there seems to be a genetic component to SAD that may be associated with variations in serotoninergic systems. These early data suggest that some aspects of SAD may be shared in part with other psychiatric disorders.

Although light treatment is widely prescribed and the necessary equipment can easily be obtained from recommended suppliers, there remains some doubt as to how much of the result is real, and how much is due to a placebo effect.

Specialists will find much of interest in this compendium. Inevitably, some information is already out of date; however, most chapters have used publications up to 2001. But the controversy regarding whether or not extra ocular light affects human rhythms does not receive sufficient critical attention. As with all multi-author books, the writing style is uneven, and there is frequent repetition of data in different chapters; in places most notably chapter 18 - there is also evidence of scant attention to proofreading. In general, however, I found it concise, easy to read and useful.

Josephine Arendt is at the Centre for

Chronobiology, Division of Clinical Biochemistry, University of Surrey, Guildford,

Surrey GU2 7XH, UK.

\title{
A knotty problem of nomenclature
}

\section{The Poverty of the Linnaean Hierarchy: A Philosophical Study of Biological Taxonomy by Marc Ereshefsky \\ Cambridge University Press: 2001. 328 pp. $\mathfrak{E} 40, \$ 65$}

\section{Peter L. Forey}

Biological classification is the science of arranging species into groups and naming those groups (nomenclature). Our day-today nomenclature is derived from a system introduced in the eighteenth century by Carl Linnaeus, who used a binomial, or two-part, name (such as Clupea harengus), to designate a species (harengus) and to suggest that a particular species belongs with others in a genus (Clupea), the two names being italicized by convention. Genera are grouped into Orders, Orders into Classes and Classes into Kingdoms, such that the diversity of life is described through a hierarchy of everinclusive ranks. Classification serves as a means of communication between different specialists within biology and beyond.

Linnaeus believed that a fixed number of species were specially created (he did allow the limited formation of new species through cross-breeding), and that genera and species have real essences - characteristics that caused their existence. The binomial was introduced to act as an aide-mémoire because, although it was impossible to remember all species names, it was possible to memorize all genera.

Our modern linnaean hierarchy is very different from that erected by Linnaeus. We use more ranks to encompass many more known species, we no longer believe that genera have essences or that species are fixed, or that one genus or family is equivalent to another. Marc Ereshefsky argues that the linnaean hierarchy is outdated, no longer meeting the theoretical and practical needs of biologists to express evolutionary relationships, and that it should be abolished in favour of a system that is rank-free and devoid of the binomial. In this he is closely allied with the authors of the draft PhyloCode, a new naming system (www. ohio.edu/phylocode). But Ereshefsky goes further in proposing species pluralism, whereby an organism can belong to more than one kind of species.

After a brief introduction to the philosophy of classification, Ereshefsky outlines the principal grouping criteria favoured by each of four systematic methods ("evolutionary taxonomy", "phenetics", "process cladism" and "pattern cladism" — his terms). Practitioners of each will find cause for argument. As a cladist, believing that organisms should be classified in a way that reflects their genealogical relationships, I find it difficult to accept that there are different kinds of morphological homology.

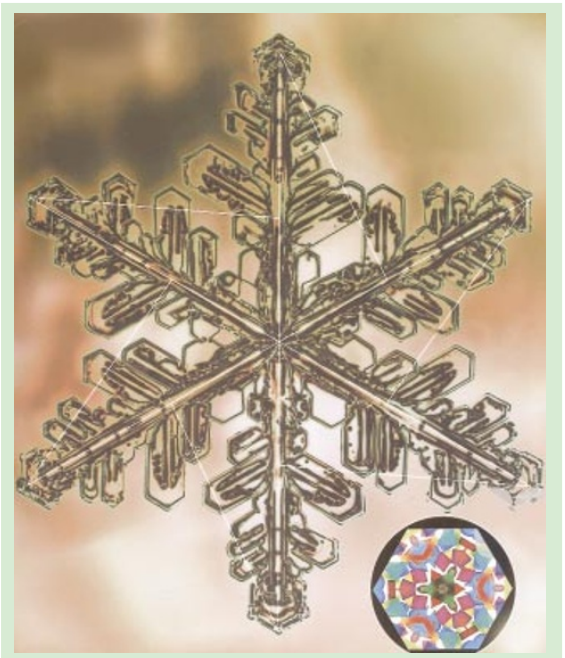

Natural maths

What governs the shape of a spider's web, the movement of waves and the pattern of a leopard's coat? In What Shape is a Snowflake? Magical Numbers in Nature (Weidenfeld \&

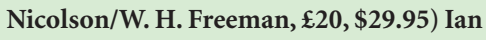
Stewart attempts to explain these natural mysteries with the aid of mathematics.
Furthermore, Ereshefsky links the many current concepts of what constitutes a species with each of these schools. Ereshefsky prefers evolutionary taxonomy and process cladism (phylogenetic systematics). (Evolutionary taxonomy groups organisms on the basis of overall similarity as well as inferred common ancestry; phylogenetic systematics groups organisms purely on inferred common ancestry.) He prefers these because they are more intricately linked to evolutionary theory, which is the cause of historical connectedness. Therefore, he argues, classification should emphasize the causal connections rather than the qualitative similarities between organisms. How our biological classifications are to be constructed in the absence of analysis of qualitative similarity or when process should take precedence over pattern is left unclear.

This general discussion leads on to arguments in favour of species pluralism in which Ereshefsky posits that any one organism or population can belong to more than one kind of species, depending on four classes of species concepts (biological, phylogenetic, phenetic and pattern-cladist). Pluralism has been criticized as being an 'anything goes' approach, so Ereshefsky leads us through philosophical arguments on how to be a 'discerning pluralist' in order to narrow down the choice of species concepts. Not surprisingly, he settles on those that mirror evolutionary taxonomy and process cladism. At this point, he offers a "menu of [philosophical] options". The problem with menu options is that the range and wording are determined by the maître d'hôtel. Some readers may choose to visit other restaurants.

The final third of the book details how the linnaean hierarchy has evolved and how it allegedly fails to meet our wish to express evolutionary relationships. In its place, he makes 11 recommendations for nomenclature, nearly all of which will have repercussions for our current international codes of nomenclature. Most of the recommendations are in the draft PhyloCode, with the addition of abandoning italicization and adopting uninomial names for species.

Overall, this book will appeal to systematists who wish to keep pattern and process closely interwoven. Whether the hierarchy is impoverished to the point of bankruptcy will depend on how successfully the recommendations in the book are taken up.

Peter L. Forey is in the Department of Palaeontology, Natural History Museum, Cromwell Road, London SW7 5BD, UK.

erratum In Brian Child's review of African Wildlife and Livelihoods: The Promise and Performance of Community Conservation, edited by David Hulme and Marshall Murphree, the reviewer's address was given incorrectly. Brian Child is at Community Conservation, Zambia Wildlife Authority, PO Box 1, Chilanga, Zambia. 